Table Showing Results of Experiments.

\begin{tabular}{|c|c|c|c|c|c|c|c|c|c|c|}
\hline \multirow[b]{2}{*}{ Disinfectant. } & \multicolumn{10}{|c|}{ Weakest strength of solution necessary to destroy the bacillus coli communis in the following times- } \\
\hline & $\begin{array}{l}\text { One } \\
\text { minute. }\end{array}$ & \begin{tabular}{c|} 
Next \\
strength \\
tested that \\
failet to \\
destroy.
\end{tabular} & $\begin{array}{c}\text { Five } \\
\text { minutes. }\end{array}$ & \begin{tabular}{c|} 
Next \\
strength \\
tested that \\
failed to \\
destroy.
\end{tabular} & $\begin{array}{c}10 \\
\text { minutes. }\end{array}$ & $\mid$\begin{tabular}{c|} 
Next \\
strength \\
tested that \\
failed to \\
destroy.
\end{tabular} & 30 & $\begin{array}{c}\text { Next } \\
\text { strength } \\
\text { tested that } \\
\text { failed to } \\
\text { destroy. }\end{array}$ & One hour. & $\begin{array}{c}\text { Next } \\
\text { strength } \\
\text { tested that } \\
\text { failed to } \\
\text { destroy. }\end{array}$ \\
\hline $\left.\begin{array}{llll}\text { dide } & \text { of } & \text { mer- } \\
y \ldots & \ldots & \ldots & \ldots\end{array}\right\}$ & 1 in 1000 & 1 in 1500 & 1 in 5000 & 1 in 7500 & 1 in 20,000 & 1 in 25,000 & 1 in 80,000 & $1 \ln 100,000$ & 1 in 200,000 & 1 in 250 \\
\hline $\begin{array}{l}\text { oride of } \mathrm{mer} \\
\ldots \\
\ldots\end{array}$ & 1 in 750 & 1 in 1000 & 1 in 2000 & 1 in 3000 & 1 in 7,500 & 1 in 10,000 & $I$ in 15,000 & 1 in 20,000 & 1 in 40,600 & 1 in 50 \\
\hline ed lime $\quad . . .1$ & 1 in 80 & 1 in 100 & 1 in 150 & 1 in 200 & 1 in & 1 in 600 & 1 in 1,500 & 1 in 2,000 & 1 in 3,000 & 1 in 4,0 \\
\hline l aldehyde ... & 1 in $30 \mid$ & 1 in 40 & 1 in $E_{0}$ & 1 in 60 & 1 in & 1 in & 1 in 150 & 1 in 200 & 1 in 250 & 1 in \\
\hline $\begin{array}{llll}\ldots & \ldots & \ldots & \ldots\end{array}$ & 1 in 10 & 1 in 20 & 1 in 30 & 1 in 40 & 1 in & 1 in & 1 in & 1 in & 1 in & 1 in \\
\hline Carbolic acid $\quad \ldots \quad \ldots$ & 1 in 10 & 1 in 20 & 1 in 40 & 1 in 60 & 1 in & 1 in & 1 in & 1 in & 1 in & 1 in \\
\hline $\begin{array}{lllll}\text { al } & \ldots & \ldots & \ldots & \ldots\end{array}$ & - & Undiluted. & 1 in 10 & 1 in 20 & 1 in & 1 in & 1 in & 1 in & 1 in & 1 in \\
\hline Medical izal $\quad \ldots \quad \ldots$ & - & Undiluted. & 1 in 10 & 1 in 20 & 1 in & 1 in & 1 in & 1 in & 1 in & 1 in \\
\hline $\begin{array}{lllll}l i n & \ldots & \ldots & \ldots\end{array}$ & - & Undiluted. & 1 in 5 & 1 in 10 & 1 in & $I$ in & 1 in & $I$ in & 1 in & 1 in \\
\hline fluid $\quad \ldots \quad \ldots$ & - & Undiluted. & 1 in & 1 in 5 & 1 in & 1 in & 1 in & 1 in & 1 in & 1 in \\
\hline 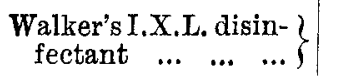 & - & Undiluted. & Undiluted. & 1 in 2 & 1 in & 1 in & 1 in & 100 & 1 in & 1 in \\
\hline indy's fluid $\quad \ldots \quad \ldots$ & - & & - & Undiluted. & 1 in 2 & 1 in & 1 in & 1 in & 1 in & 1 in \\
\hline Sanitas" fluid $\quad$... & - & $\mathrm{U}_{\mathrm{Z}}$ & - & Undiluted. & Undiluted. & 1 in 2 & 1 in & 1 in $\quad 31$ & 1 in & 1 in \\
\hline $\begin{array}{llll}\text { Boric acid } & \ldots & \ldots & \ldots\end{array}$ & - & Saturated. & - & Saturated. & - & Saturated. & - & Saturated. & - & Saturated. \\
\hline
\end{tabular}

experiments-i.e., where the bacilli are freely exposed to the action of the disinfectant in solution, no albuminous matter being present. In the actual practice of disinfection such conditions are never met with, the most important difference being the presence of albuminous material in greater or less quantity. Especially does this apply to the case of perchloride of mercury, which forms a definite combination with albumin, resulting in the formation of a comparatively inert albuminate of mercury, and thus, to maintain its efficiency, the strength of the solution would require to be increased in proportion to the amount of albuminous matter present.

Biniodide of mercury.-This was brought into solution by the addition of iodide of potassium in quantity just sufficient to dissolve it, a stock solution of 1 part of biniodide in 500 of distilled water being first prepared, from which the more dilute solutions were afterwards obtained by the addition of the requisite proportion of ordinary tap-water. It will be noted that the germicidal power of this drug is far superior to that of any other used in these experiments, and as it does not precipitate with albumin the results obtained should hold good even in the presence of albuminous material, thereby contrasting with the perchloride of mercury.

Chlorinated lime (commonly called "chloride of lime").This is a white powder which is only partially soluble in water, and after standing for a little the insoluble portion falls to the bottom. This was kept in suspension in these experiments by frequent shaking of the glass vessel containing the threads immersed in the solution, but I also found that the germicidal power was not in any way altered by previously filtering the solution so as to remore this insoluble portion. In the stronger solutions of this substance not only are the bacilli on the threads all killed but the threads themselves are destroyed and in a short time almost all trace of them disappears.

Formal aldehyde.-The solutions of this substance were prepared from Schering's formalin, which is a 40 per cent. solution of formal aldehyde in water, the latter itself only existing in the gaseous state. It must be clearly understood that the proportions stated in the accompanying table refer to formal aldehyde and not to formalin.

Izal and medical izal.-These two coal products are prepared by Messrs. Newton, Chambers, and Co., the latter being a refined preparation of the former specially adapted to medical and surgical use. I found no difference between them as regards their germicidal properties. It should be stated that the proportions given in the accompanying table refer to the product as sold for use and not to the proportions of izal oil, of which "izal" disinfectant is an emulsion containing 40 per cent.

Boric acid.-This substance has no claim to be regarded as a disinfectant, since its saturated solution failed to destroy the bacillus coli communis in any of the allotted times. Manchester.

\section{ACUTE GLOSSITIS COMPLICATING A CASE OF TYPHOID FEVER.}

BY H. CAMPBELL THOMSON, M.D., M.R.O.P. LOND.,

ASSISTANT PHYSICTAY AND PATHOLOGIST TO THE MIDDLESEX HOSPITAL PHYSICLAN TO OUT-PATIENTS AT THE HOSPITAL FOR EPILEPSY AND PARALYSIS, REGENT'S-PARK.

THE patient, a woman aged 34 years, suffering from typhoid fever, was admitted into the Middlesex Hospital on Nov. 17th, 1899, under the care of Dr. J. Kingston Fowler, to whom I am indebted for permission to make use of the clinical notes of the case. The early symptoms of the attack consisted of weakness, languor, pain in the back, and shivering. The bowels were confined at first and later they became more freely opened, but diarrhœea was never a troublesome factor. There was no vomiting. The blood showed Widal's reaction and the urine gave Ehrlich's test. There was a well-marked rash on the abdomen.

The patient was from the first very seriously ill and in spite of all treatment her condition became gradually worse till on Dec. 16th the pulse was scarcely perceptible and she was evidently in extremis. On the 17th, at 7 P.M., the tongue was first noticed to be swollen and examination showed the swelling to be confined to the left balf of the organ. This condition must have arisen very rapidly as the tongue had previously been examined at midday and there was then no sign of any swelling. The swelling was firm and did not fluctuate, the mucous membrane over it was reddened, it was tender when touched, and gave rise to some difficulty in swallowing. At 10 P.M. on the same evening the swelling had increased and it now involved the right half of the tongue. The size of the swelling made it advisable to take some steps to try to reduce it, and accordingly after the part had been anxsthetised with cocaine a grooved needle was passed into the tumour, but only a little blood escaped. The patient's general condition, however, was so bad that it was not considered advisable to take any further measures and a few hours later death occurred. A post-mortem examination was made on the following day and extensive intestinal ulceration was found which bad terminated in general peritonitis from a perfora. tion at the lower end of the ileum. The tongue was swollen, especially the left half, and the mucous membrane over it was reddened; there were also one or two superficial 
ulcerations on the dorsum of the tongue. On section the tissues were reddened and swollen, but there was no suppuration present.

The condition is of interest both on account of its rarity and its importance, for it may be a rery formidable complication, and in this case had the patient not succumbed to the intestinal lesions vigorous measures would, no doubt, have had to be taken to reduce the swelling.

A case which occurred in Dr. Osler's clinic has been recorded by MacCrae, ${ }^{1}$ in which glossitis was the first symptom of a relapse after 24 days of normal temperature. The tongue was red, inflamed, symmetrically enlarged, markedly tender, and somewhat indurated as far back as could be felt. Cultures taken from the left half gave a negative result, and after puncturing, the swelling of this half diminished, showing, as MacCrae thinks, the line of treatment which should be pursued. In this instance the patient made a good recorery. MacCrae states that this was the only case of glossitis which occurred in over 700 cases of typhoid ferer treated in the Johns Hopkins Hospital. He quotes Nichols as having recorded a case of "septic infection in typhoid fever" in which two days before death swelling of the right half of the tongue was noted. This case ended fatally. At the necropsy the right half of the tongue was red and swollen and on section small abscesses and hæmorrhages were seen. Cultures yielded streptococci and the bacillus coli.

The cause of glossitis in the course of typhoid fever is an interesting question. The large majority of the cases probably arise from secondary local infections, and the presence of superficial ulcers of the tongue is suggestive of this mode of origin in the case $I$ now record. Other cases, however, would seem to be part of a general infection-as, for instance, MacCrae's case in which the glossitis was the first symptom of a relapse after 24 days of normal temperature.

Queen Anne-street, W.

\section{IMPERFORATE HYMEN AND RETAINED MENSTRUAL ACCUMULATION.}

\section{By HUGH HOWIE BORLAND, M.B., C.M. GLasg., D.P.H. CANTAB.}

LATE HOLTE SURGEON, GLASGOW MATERTITY HOSPITAL.

I WAS called on Jan. 4th, 1900, to see a girl, aged 13 years and nine months, who was complaining of diarrhcea, rigors, and abdominal pain. The history was that on Dec. 30th, 1899, she began to suffer from diarrhoea apd on the following day abdominal pain set in. This state of matters continued more or less until Jan. 4th, when diarrhcea, bearing-down pains, dysuria, and, finally, retention of urine supervened. The mother stated that the girl had always enjoyed good health. She had never menstruated, but as bearing upon her present illness it was noticed when a child that there was a "large blue vein" about the lower aspect of the genitals. Nothing, however, in the way of operation had been done for it. The girl was in a condition of extreme distress, crying out with agony and throwing herself about in bed when paroxysmal pains set in. She was a well-nourished and well-developed girl with womanly configuration, having large, plump, and wellformed breasts. The lower aspect of the abdomen showed a large, round, globular tumour which rose out of the pelvis, reached from the pubes to two inches above the umbilicus, and was so tense and resistant that it simulated the gravid uterus. Fluctuation could not be elicited. The vulva was greatly bulged downwards and the perineum was distended. On separating the thighs, but without everting the labia minora, the vaginal orifice was seen to be completely occluded by a bulging membrane across which some minute blood-ressels were traced. The colour of the membrane was that of a bluish plum; it measured two and a half inches and one and a half inches from before backward and had a convex projection one inch in extent. Fluctuation was here easily obtained. There was a considerable bulging of the lower aspect of the rulva and adjacent parts. There was no dilatation of the anus, although there had been severe diarrhœa. Rectal examination revealed that the lower lumen of the bowel had been extensively encroached upon by a large balloon-like mass, which was smooth and elastic. This tumour had not only pressed upon the bowel, but had pushed up the anterior aspect of the vulva to such an extent that the meatus urinarius was practically occluded, causing complete retention of urine.

On a catheter being passed 40 ounces of urine were drawn off, and to clear out the bowels thoroughly castor oil was ordered. The parts were also prepared for operation next morning. In the interval, however, previously to my arrival the dense membrane had become perforated in the median line. This aperture was only able to admit a small probe, yet a considerable amount of treacle-like substance had oozed out, and thus there had come about that slow aspiration which most authorities recommend in treating such cases. The vulva and perineum were again thoroughly cleansed by a solution of lysol ( 1 in 200). An incision with a sterilised knife was then made from before backward in the entire extent of the membrane in the median line. The index finger was introduced into the now open vaginal orifice in order to induce a free flow of the retained menses. The mucous membrane of the utero-vaginal canal was found to be perfectly smooth and devoid of rugæ. Suprapubic pressure was aroided during the evacuation of the fluid, and to prevent re-uniting of the cat surface of the membrane a sterilised perforated glass tube containing iodoform and boric powder was inserted into the aperture and retained in situ. Pads of wood wool were then placed over the vulva and perineum and fixed in position with a double $T$ bandage. The patient was instructed to put gentle pressure on the glass tube to keep it in position when passing urine, and her mother, the nurse, was instructed to cleanse the parts most carefully thereafter with ly sol solution on each occasion. For diet the patient had milk only, and two grains of quinine were given every three hours. The recumbent posture was enjoired unless while taking food when the semi-recumbent position was to be adopted.

On Jan. 6th I found that the patient had passed a gond night; her temperature was $98^{\circ} \mathrm{F}$. and her pulse was 89 . I removed the glass which was half filled with the treacle-like material. Examination per rectum showed that the balloonlike mass had disappeared. Examination per vaginam failed to detect the os uteri. There were now, however, well-marked rugæ felt longitudinally in the previously smooth-lined uterovaginal canal. The retained menses were apparently well drained. The glass tube was sterilised and again inserted and the same kind of dressings were applied. The subsequent history of the case was quite uneventful. There was no rise of temperature and the girl was allowed to get up on Jan. 12th, on which date there was no discharge of any kind in the tube or on the dressings. On the 15 th examination per vaginam revealed rugæ almost of a scirrhus-like nature. The uterus was found to be normal and the os closed. It was directed that the glass tube should be inserted twice a week for some time. On Feb. 17th (six weeks after the operation had been performed) the girl menstruated normally, being poorly for four days.

It will be observed that the patient had reached puberty, although she was barely 14 years of age, and the accumulation must have been going on for many months to judge from the size of the abdominal swelling. It contained over three pints of altered blood which continued to run for several days as the uterus slowly contracted. The girl was quite unaware that there was anything abnormal and stated most clearly that there had been no monthly periodic occurrence of pelvic or bearing.down pains whatever.

Previously to the era of asepsis and antiseptics incision of an imperforate hymen was not infrequently followed by fatal results from septic absorption. Gradual withdrawal of the fluid enables the uterus to accommodate itself to its diminish. ing contents, but, as Lewers has pointed out, if it is rapidly emptied contractions are set up, some of the fluid with septic matter from the air may be forced along the Fallopian tubes into the peritoneum, and death from peritonitis may result. Newmilns, Ayrshire.

The Colne Town Council has decided to erect a new infectious diseases hospital at the Old Farm, near Colne, at an outlay of $£ 8530$. Accommodation will be provided for 26 beds. 